\title{
Experimenting in School Science Lessons (ESSL) - A Concept for a Teacher Trainees' Practical Course
}

\author{
Kai Wolf, Thomas Waitz \\ Georg-August-University Göttingen, Germany
}

\begin{abstract}
Typically, teacher trainees' practical courses at universities focus on a conceptual understanding of experimental outcomes and the necessary manual skills to conduct experiments according to a lab manual. However, they rarely focus on a critical reflection of the didactical functions which experiments in science lessons could provide. Therefore, we designed a practical course concept called "ESSL Teacher Trainees' Practical Course" which considers the facilitation of didactical skills for the integration of experiments into school science lessons. This paper describes this course concept by the example of its application to a practical course for future chemistry teachers.

Our evaluation of the concept is based on a written survey, which revealed that students rated the acquired skills relevant and helpful for their future teaching profession.
\end{abstract}

\section{Introduction}

Since experimenting is considered as the fundamental method of knowledge acquisition in empirical science, planning, processing and interpreting experimental results are crucial skills in most science disciplines. Therefore, Science Education Standards and research agree that science education at all levels should focus on these basic skills [1-3]. For instance, Hart, Mulhall, Berry, Loughran \& Gunstone state that "[1]aboratory work is almost ubiquitously seen as being of great importance to science education, by some as almost the defining characteristic of this component of the school curriculum" [2]. Additionally, experimenting itself might raise students' interest for science in general and motivate them to profoundly engage in science lessons [4]. Furthermore, experiments are often conducted in groups, allowing students to acquire and practice teamwork skills [5]. Due to the importance of experiments in science education, prospective science teachers need to be well prepared during their studies in order to effectively integrate experiments into their lessons [2]. In accordance with NSTA (National Science Teachers Association) Preservice Science Standards, we suggest that the education of science teachers should include the following aspects:

- a critical reflection on the role of experiments in science and science classes,
- mastery in the performance of experiments,

- mastery in the demonstration of experiments,

- critical reflection of experiments according to didactic aspects (contextualization, age appropriateness, etc.),

- skills to adapt experiments according to teaching needs and

- classroom organization in experimental lessons [6].

In contrast, many teacher trainees' practical courses at universities consist of a set of school experiments that have to be completed by following a lab manual [7]. While this course design might contribute to the students' subject-specific knowledge of experiments, it neither forces the development of didactical skills nor mediates an inquiry character of experimenting. Therefore, we designed a practical course concept which is meant to qualify students to effectively integrate experiments into school science lessons. The aim of this paper is to provide a description of our concept called "ESSL Teacher Trainees' Practical Course" and its application to a practical course for prospective chemistry teachers at the University of Göttingen. Additionally, we evaluated the employability of our course via a short survey [8]. The aim of this survey was to investigate if the students who participated in this course have acquired the needed skills to integrate experiments into their chemistry lessons and rate these skills as important for their future teaching.

\section{The ESSL Teacher Trainees' Practical Course Concept}

Figure 1 displays the structure of the practical course which consists of four phases with a total duration of 20 days.

\subsection{Introductory Phase}

The first phase consists of a two day introductory workshop, where students cooperate to acquire knowledge about the demonstration and didactical function of experiments, as well as criteria to integrate experiments into science lessons.

To demonstrate experiments, Gestalt Laws of Perceptual Organization [9] and the possibilities of visual media such as OHPs (Overhead Projectors) or cameras are considered in the workshop. 


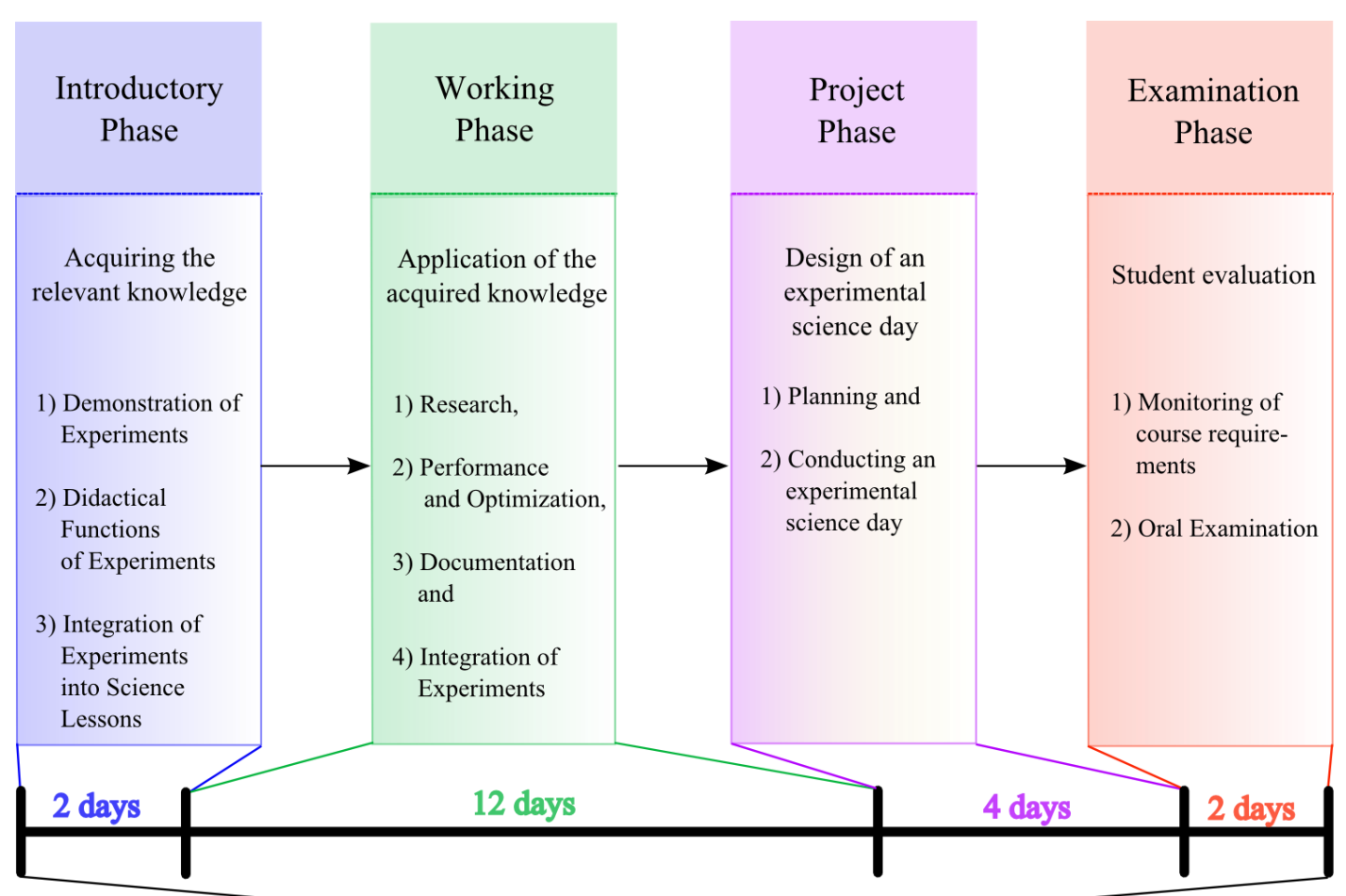

20 days

Figure 1. The Structure of the ESSL Teacher Trainees' Practical Course Concept

The Gestalt Laws have been applied to the design of experimental setups, which resulted in the following proposals:

a) Omit unnecessary devices. Every object that does not belong to the experimental setup should be removed since it disturbs the perception of the experiment.

b) Consider a dynamic from left to right. Since reading and writing in the western culture is traditionally performed from left to right, it is very helpful for students if they can observe a reaction that proceeds from left to right from their perspective.

c) Use a symmetric experimental setup, if possible. Symmetric figures are easier to perceive than non-symmetric figures.

d) Use linear connections between different devices. Linear connections are easier to perceive than crooked connections.

e) Use a clear contrast between setup and background. The devices of the experimental setup must contrast clearly from the background so that the experiment can be observed appropriately [10].

Figures 2 and 3 show different experimental setups for the same experiment. The left image takes into consideration proposals a) and e) respectively, whereas the right image does not.
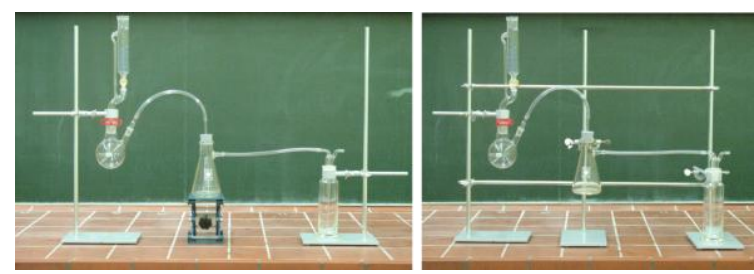

Figure 2. Example pictures for proposal a): omitting needless devices.
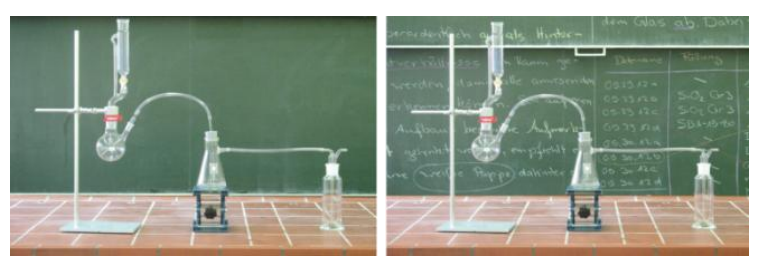

Figure 3. Example pictures for proposal e): clear contrast between setup and background.

These two figures show that considering the Gestalt Law proposals results in better observability of the experimental setup, which is essential students' understanding. 
Furthermore, possibilities for improved and amplified visualization by means of an OHP or by camera and beamer are discussed. These technical devices ensure that every pupil in the classroom is able to observe demonstrated experiments appropriately while material costs are also minimized.

However, the use of an OHP is limited to experiments with transparent solutions and photoelectric or photochemical processes. For example, the radical bromination of heptane can easily be visualized and initiated by an OHP (see Figure 4).

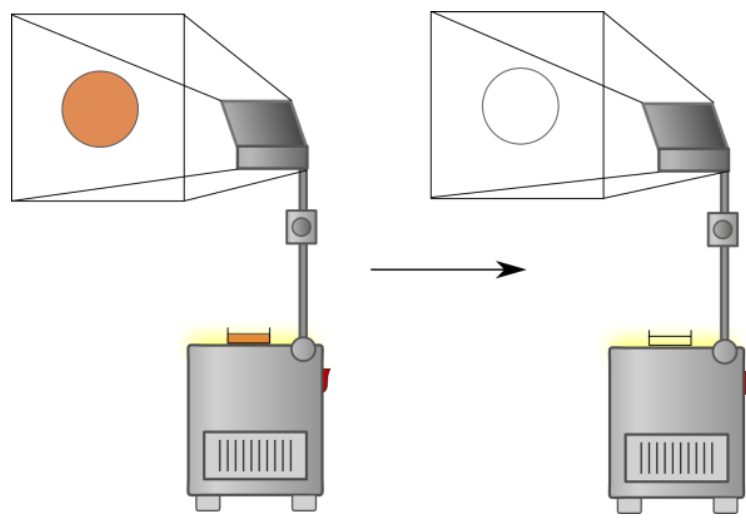

Figure 4. The bromination of heptane via an OHP. During the bromination process, the brown colour of bromine changes.

With respect to the functions of experiments, students learn to differentiate between four basic experimental functions:

- The discovery of phenomena and laws (e.g. the electrochemical series of metals),

- Evoking a cognitive conflict (e.g. comparing the conductivity of a salt solution and a sugar solution in junior classes),

- Validation of hypothesis (e.g. predicting the emergence of carbon dioxide when hydrochloric acid is given to a solution of carbonate) and

- Fascination of students (e.g. showing the Bengal fireworks without clarifying the basic chemical background of the reactions).

At this point, we would like to stress that the first three functions point out the role of experiments in science classes, whereas the last function should be treated carefully since these so called "wonder" experiments, which are not explained or discussed in depth in the lessons, might evoke misconceptions about the nature of science [11].

Secondly, students learn to differentiate between teacher-conducted and student-conducted experiments. The former are used to show dangerous, time- and material-consuming experiments. Usually, the function "fascination of students" is pursued with these kinds of experiments, although other functions can also be realized. However, due to the importance of experimenting in science it is also necessary that students learn to conduct experiments on their own. Therefore, the latter are used to focus on facilitating experimental skills, motivating students and conducting inquiry tasks.

Thirdly, the following six criteria for integrating experiments into science lessons are also acquired in the workshop via group-work and poster presentations. These criteria should help in deciding whether or not an experiment is suitable for a certain grade level and if it should be performed by the teacher or the student.

1) Safety of experiments: Are the materials authorized for a certain grade? Are there any safer alternative experimental setups? Are students allowed to work with the respective chemicals?

For instance, the so called Beilstein test to detect alkyl halides has been labelled unsuitable as a student-conducted experiment in German schools due to different dioxin by-products. Therefore, the test should be teacher-conducted. [12]

2) Financial and temporal costs: How can material costs be minimized? How much time is required for the performance and analysis of the experiment?

For example, to show the reactions of alkali metals with ethanol it is not necessary to buy purified ethanol gained from alcoholic fermentation because the less pure industrial ethanol is also appropriate and cheaper.

3) Clarity of effects: Is there a clearly observable difference between the start and the end of an experiment?

When comparing the typical introductory experiments of the reaction of iron and sulphur with copper and sulphur, it can be seen that iron sulphide resembles elemental iron whereas the blue colour of copper sulphide clearly differs from the red coloured elemental copper and the yellow coloured elemental sulphur. Therefore, the latter experiment seems to be more appropriate according to this criterion.

4) Contextual relevance in the respective grade and class: What does the experiment show? How does the interpretation of the experiment relate to former and subsequent lessons? How is the experiment implemented in the respective curriculum?

For example, the reaction of copper with sulphur can be discussed in grade $7 / 8$ as a chemical reaction in general (since there is a new, blue substance after the reaction accompanied by a transfer of energy) and in grade $9 / 10$ on a more advanced level as a 
redox reaction where copper acts as an electron donor and sulphur acts as an electron acceptor.

5) Difficulty of performance: Are pupils able to perform the experiment? What kind of support do they need?

Especially when pupils have to set up complex experiments with many glass devices (such as the experiment with gas development given in Figure 5), they might need teacher assistance or a video explanation or animation.

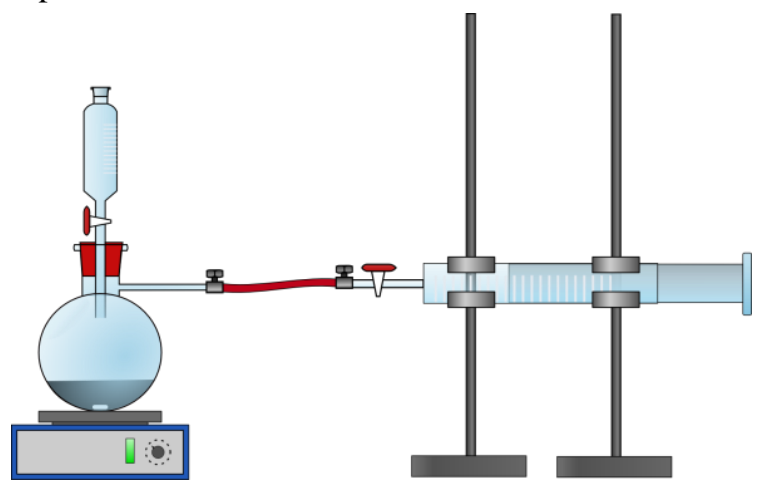

Figure 5. The experimental setup for a gas development reaction

6) Classroom organization for an experimental lesson: Do the students or the teacher perform the experiment? Do students work in groups or on their own? Is each group conducting the same experiment under different conditions (e.g. determining the velocity of the reaction between magnesium and hydrochloric acid at different $\mathrm{pH}$-values)? Does each group conduct a different experiment in the scope of a certain topic (e.g. determining the oxidative activity of different metals)?

\subsection{Working Phase}

In the second phase, students are faced with the open tasks to research, conduct, modify, document and present experiments on a given topic and for a certain grade level. Since the topics are typically fundamental components of the school curricula, we can consider the task authentic for prospective school teachers. To keep this authenticity, it is important that the laboratory equipment is comparable to that of schools. The topics of our practical course for prospective chemistry teachers are given in Table 1.

Table 1. Sampling of topics treated in the practical course

\begin{tabular}{|l|l|}
\hline Grade & Topics \\
\hline
\end{tabular}

\begin{tabular}{|c|c|}
\hline \multirow{5}{*}{$5 / 6$} & states of matter (solid, liquid, gas) properties of \\
substances (combustibility, solubility, conductivity, \\
magnetizability); acidic and alkaline solutions, \\
material separation, water cycle, water conditioning, \\
air as a mixture of gases, fire fighting, cosmetic \\
products, properties of paper, energy resources
\end{tabular}

\begin{tabular}{|c|c|}
\hline $7 / 8$ & $\begin{array}{c}\text { diffusion; density and its dependence on temperature } \\
\text { and pressure, homogeneous and heterogeneous } \\
\text { mixtures, characteristics of a chemical reaction, law } \\
\text { of conservation of mass and stoichiometry, } \\
\text { endothermic/exothermic reactions; activation energy } \\
\text { of reactions; catalysts; properties of and reactions } \\
\text { with oxygen gas, corrosion, properties of carbon } \\
\text { dioxide, metals and ores, precipitation reactions, } \\
\text { energy and its conversion }\end{array}$ \\
\hline
\end{tabular}

\begin{tabular}{|c|c|}
\hline \multirow{1}{*}{} & $\begin{array}{c}\text { akali and alkaline earth metals; halogens; detection } \\
\text { reactions for alkali metals, halogens, oxygen and } \\
\text { hydrogen, acid-base- reactions, properties and } \\
\text { reactions of sulfonic acid, acid and alkaline } \\
\text { substances in the household, reactions of acids with } \\
\text { metals and metallic oxides, acid-base titration, } \\
\text { electrolysis, fuel cells, determination of water } \\
\text { hardness, properties and reactions of aliphatic } \\
\text { compounds, properties and reactions of alcohols } \\
\text { (e.g. elimination), alcoholic fermentation, } \\
\text { determination of alcohol concentrations, oil refining, } \\
\text { fossil fuels and renewable energies }\end{array}$ \\
\hline \multirow{10}{*}{$11 / 12$} & $\begin{array}{c}\text { properties and reactions of unsaturated } \\
\text { hydrocarbons, aldehydes, ketones; carbon acids, } \\
\text { esters and ethers, nutrition; surfactants; dyes and } \\
\text { cosmetic products, kinetics; chemical equilibrium; } \\
\text { advanced concepts of redox reactions, corrosion, } \\
\text { batteries and accumulators, galvanization }\end{array}$ \\
\hline
\end{tabular}

Every student has to complete a set of four tasks with a minimum of four experiments every three days. On the first two days, students have time to search for, conduct and modify experiments as well as elaborate their lab reports and presentations. On the last day, every student has to demonstrate at least two of their four experiments to the course participants in a presentation and submit the lab reports of all their experiments to the teaching assistants. After the presentation, they are provided with instant oral feedback according to the appropriateness of their chosen experiments, their demonstration skills as well as their overall appearance. Also, they are provided with written feedback on their content and the formal aspects of their lab reports.

While processing the tasks, students are obliged to apply their knowledge from first phase. In the process of searching for adequate experiments, they need to apply the criteria 1 to 4 presented above. When writing their lab reports, students need to demonstrate knowledge about the functions of experiments and criteria 4 to 6 , since they are not only forced to describe the conducted experiments but also to discuss possible ways of integrating the experiments into lessons for the respective grades. Therefore, it is also important to work with the curriculum because it specifies the learning goals for certain grades. Finally, the presentation of the experiments requires knowledge about an appropriate form of demonstration. 
To clarify the different steps and their realization in the course, an exemplary treatment of the topic "Conductivity as a Property of Substances" for grades $5 / 6$ by one of our students will be described. After he was given the topic, his two day period of preparation started. First of all, he began researching using different resources. During this research process, he also had to look up the learning goals in the appropriate curriculum (criterion 4). Amongst many, he found two experiments that he deemed adequate for the respective grades: "Conductor or Non-Conductor?" [13] and "Dependence of the Conductivity of Metals on Temperature" [14].

The first can be used to proof the conductivity of everyday or laboratory objects such as pencils, nails or a glass rod. The chosen experimental setup is depicted in Figure 6. The setup is rather easy: a simple series circuit consisting of a voltage source (battery), an electric propeller, electric cables and two crocodile clips. battery

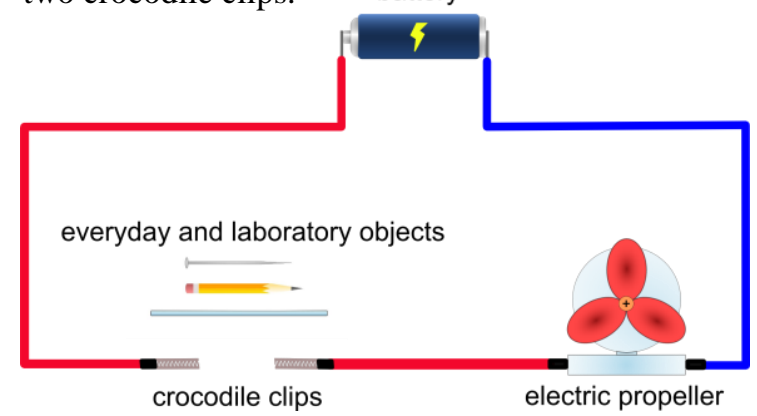

Figure 6. Experimental setup of the experiment "Conductor or Non-Conductor?"

Figure 7 shows an alternative setup suited to additionally test the conductivity of everyday liquids and solutions like water, oil, salt solution or sugar solution. battery

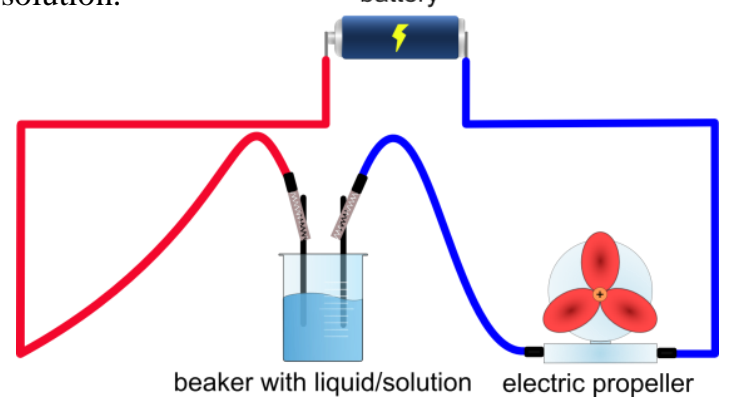

Figure 7. Additional experimental setup of the experiment "Conductor or Non-Conductor?"

This experiment is considered appropriate for grades $5 / 6$ and can be performed by students due to the following reasons (criterion 6):

- It does not entail high risks since it can be conducted with a maximum voltage of 4-5 volts (criterion 1),
- it has very low financial costs since everyday objects and substances are used and the setup does not take much time (criterion 2),

- it has visible outcomes due to the indication of conductivity by the electrical propeller (criterion 3),

- it fits in the grade $5 / 6$ curriculum since the conductivity of substances is proven on a phenomenological basis (criterion 4) [15] and

- $\quad$ it is easy to perform due to the simple setups (criterion 5).

A possible classroom organization might be that pupils test the conductivity of two objects or liquids in groups of 3-4 before the results are discussed in class (criterion 6).

Which functions can the experiment have? It can be used to discover the properties of substances (e.g. "Metals are conductive, glass is not."), to evoke cognitive conflicts (e.g. "Why is a salt solution conductive whereas a sugar solution is not? They are both prepared by solving a white crystal-like substance in water...") and also to validate certain hypotheses (e.g. "Since pencil lead is conductive, coloured lead might also be conductive...").

The second experiment, whose setup is shown in Figure 8, can be performed to show students that the conductivity of different metals (e.g. copper and iron) changes according to their temperature; when they are heated, the electrical resistance rises and the propeller stops turning.

This experiment is also suitable for grades 5/6, but should be teacher-conducted (criterion 6):

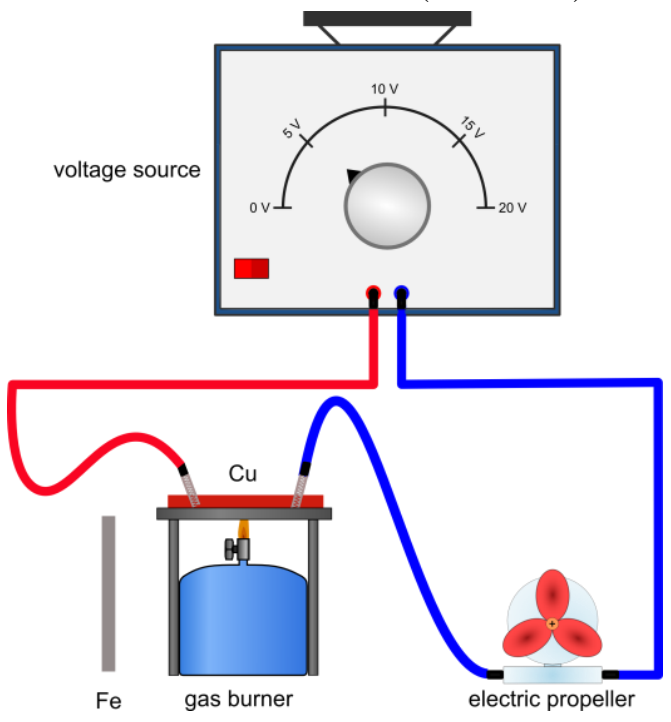

Figure 8. The experimental setup of the experiment "Dependence of the Conductivity of Metals on Temperature"

- It entails few risks since there are no explosives or corrosive substances (criterion 1), but students have to get accustomed to working with a gas burner and heated substances (criterion 5). 
- $\quad$ It is inexpensive, but it requires more time to set up and perform in comparison to the first experiment,

- the outcome is visible enough due to the indication of conductivity by the electrical propeller (criterion 3) and

- $\quad$ it is in accordance with the curriculum since it still deals with the properties of substances on the basis of phenomenology (criterion 4).

After this criteria-based choosing and performing of experiments, modifications can be done. For example, to modify the former experiment, the student summarized everyday objects, liquids and solutions that pupils might test (e.g. a ruler, a surfactant solution etc.).

In a next step, the student had to document his experimental phase according to a given outline that consists of

- $\quad$ the title of the experiment (e.g. "Conductor or Non-Conductor?"),

- a list of materials (e.g. "battery, electric cables, ...),

- the experimental section (including the procedure and a graphic/photograph of the experimental setup)

- the observation section (e.g. "When the crocodile clips are connected to the pencil, the propeller is turning.") and

- the analysis (e.g. "A pencil is conductive.")

Finally, the student demonstrated the experiments in front of the class. In order to do this, he had to set up the experiment in accordance to the Gestalt Laws of Perception. Depending on the room size, using a camera might also be helpful.

\subsection{Project Phase}

In the third phase, students are faced with another open and authentic activity that has to be solved in groups: The design of a science experiments day for pupils. While planning this event, students need to independently elaborate a concept for a given topic, e.g. "Chemistry of Fire \& Flames" or "Nanochemistry", choose appropriate experiments, plan the laboratory phase and as well as the promotion of the event. In the end, students conduct the science day in accordance to their own developed itinerary. In our practical course for future chemistry teachers, this science day is integrated into the faculty's annual open house.

\subsection{Examination Phase}

The examination and evaluation of our students is the fourth and last phase of the concept. As a prerequisite for the examination, students have to give four presentations and (if necessary) revise the four lab reports. After that, students have to take an oral exam based on the content of the first phase, their experiments and the didactical discussions in their lab reports. Special focus is placed on the conceptual understanding and application of the aforementioned criteria to integrate experiments into science lessons.

In summary, students should be able to (1) work independently, (2) research didactically relevant experiments and integrate them into certain classroom settings as well as (3) conduct and demonstrate them.

\section{Evaluation of the Course}

In order to evaluate the employability of our practical course, we conducted a short written survey with all students in the summer semester 2012 ( $\mathrm{n}=$ 16). The students were asked the following question:

"In your opinion, what are the most important skills you have learned in this course?"

The analysis followed a mixed coding procedure. First, similar responses were grouped together. This resulted in a total amount of eight codes. In a second step, the codes were assigned to the learning goals described above. To maximize the reliability and objectivity, two people separately coded the material. Differences between their codes were brought into harmony through discussion. For the purpose of transparency, Table 2 shows example quotes of students' responses and the corresponding codes.

Table 2. Examples of students' responses and the corresponding codes

\begin{tabular}{|c|c|}
\hline Example of Students' responds & Corresponding Code \\
\hline "I learned how to find and revise & Finding and Revising \\
experiments which are appropriate & Appropriate \\
for a certain grade." & Experiments \\
\hline
\end{tabular}

\begin{tabular}{|c|c|}
\hline $\begin{array}{c}\text { "The demonstration of experiments } \\
\text { in front of our group was very well } \\
\text { practiced and improved." }\end{array}$ & $\begin{array}{c}\text { Appropriate } \\
\text { Demonstration of } \\
\text { Experiments }\end{array}$ \\
\hline
\end{tabular}

\begin{tabular}{|c|c|}
\hline "The preparation of experiments in & \\
an autonomous way was very & Independent Working \\
helpful." &
\end{tabular}

\begin{tabular}{c|c}
\hline "My ability to take criticism has \\
improved a lot."
\end{tabular}$\quad \begin{gathered}\text { Giving and Taking } \\
\text { Feedback }\end{gathered}$


Figure 8 shows the coded responses and the quantity of their occurrence. It becomes obvious that

- most students emphasize the importance of finding, revising and demonstrating experiments with special consideration for safety regulations (number 1-3),

- many students state that independent working in general and appropriate usage of the curriculum are essential for their future profession (number 4-5) and

- at least some students stress that it is important to appropriately document experiments, to differentiate between teacher-conducted and student-conducted experiments and to be able to give and take feedback on presentations and lab reports (number 6-8).

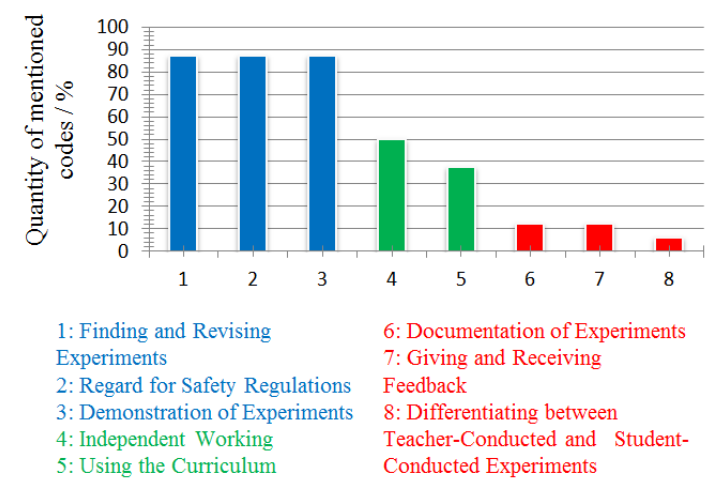

Figure 8. Coded responses and the quantity of their occurrence

Apart from that, we find that the students' responses can be assigned to all of our three learning goals, which are shown in Figure 9.

- $\quad$ The code "Independent Working" was named to our respective first learning goal and therefore assigned to it.

- The codes "Finding and Revising Experiments", "Regard for Safety Regulations", "Using the Curriculum" and "Differentiating between Student-Conducted and Teacher-Conducted Experiments" were assigned to our second learning goal called "Research and Integration of Experiments".

- Finally, the codes "Demonstration of Experiments", "Documentation of Experiments" and "Giving and Receiving Feedback" could be assigned to our third learning goal called "Performance and Demonstration of Experiments".

\section{Conclusion and Outlook}

Within this report, we described a concept for a university practical course intended to enable prospective science teachers to incorporate experiments into their lesson planning. Important

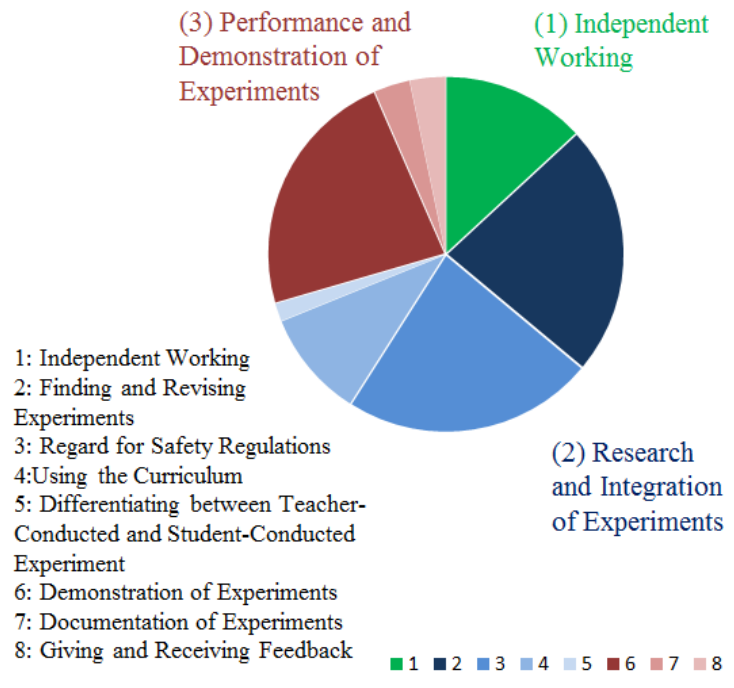

Figure 9. Assignment of the coded responses to our learning goals

aspects of this process are the finding of experiments in literature, the critical selection of experiments for certain learning goals and the demonstration of experiments in the classroom as well as a focus on self-regulated working in an authentical setting. Additionally, the results of our written survey reveal that students emphasize the importance of skills they acquire with respect to their future teaching profession.

However, these results should be treated with caution since the number of participants is not representative and standardized pre- and post-tests of skills were not conducted. Further surveys should focus on the design of such a skill test that is suited to the course goals.

\section{Acknowledgements}

We thank the Fonds der Chemischen Industrie for financial support.

\section{References}

[1] http://www.education.gov.uk/schools/teachingand-learning/curriculum/primary/b00199179/science/ks1/sc1. (May $30^{\text {th }}, 2013$ )

[2] Hart, C., Mulhall, P., Berry, A., Loughran, J., \& Gunstone, R., (2000), What is the purpose of this experiment? Or can students learn something from doing experiments? Journal of research in science teaching, 37 (7), pp. 655-675.

[3] Hodsen, D., (1988), Experiments in science and science teaching. Educational Philosophy and Theory 20 (2), pp. 53-66.

[4] Holstermann, N., Grube, D. \& Bögeholz, S., (2010). Hands-on Activities and Their Influence on Students" 
Interest. Research in Science Education 40 (5), pp. 743757.

[5] Brown, H. \& Ciuffetelli, D.C., (2009). Foundational Methods: Understanding Teaching and Learning. Toronto.

[6] http://www.ncate.org/Standards/ProgramStandardsandReportForms/tabid/676/Default.aspx. (March 10, 2013)

[7] Kirschner, P.A., (1992). Epistemology, practical work and Academic skills in science education. Science \& Education, pp. 273-290.

[8] Johnson, B. \& Cristensen, L., (2011). Educational Research: Quantitative, Qualitative and Mixed Approaches. Thousand Oaks, Calif.

[9] Wertheimer, M., (1923). Untersuchungen zur Lehre von der Gestalt II. Psychologische Forschung 4, pp. 301350 .

[10] Schmidkunz, H., (2002). ,[Die Anwendung der Gesetze des Sehens auf] Demonstrationsexperimente', in Konkrete Fachdidaktik Chemie, Oldenbourg: München, pp. 301-306.

[11] Silverman, M. P., (1989). Two sides of wonder: Philosophical Keys to the motivation of science learning. Synthese 80, 43-61.

[12] http://www.chemieunterricht.de/dc2/gefahr/beilstpr.html. (May $30^{\text {th }}, 2013$ )

[13] Saan, A. V., (2010). 365 Experimente für jeden Tag. moses: Kempen, p. 191.

[14] http://daten.didaktikchemie.uni-bayreuth.de/experimene/standard/0605_leitfaehigkeit_metall.html.

(May $30^{\text {th }}, 2013$ )

[15] Niedersächsisches K. M., (2007). Kerncurriculum für das Gymnasium. Schuljahrgänge 5-10, Unidruck, Hannover, pp. 18-51. 